\title{
Comparing the effectiveness of vitamin D plus iron vs vitamin D on depression scores in anemic females: Randomized triple-masked trial
}

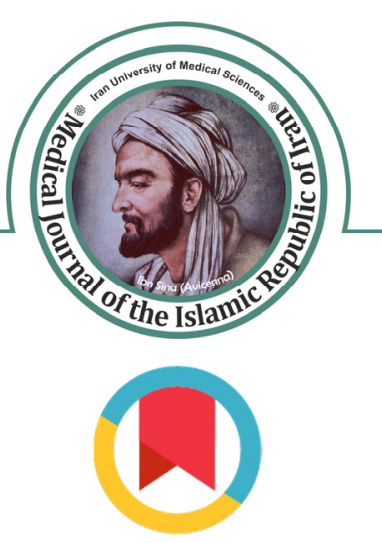

\author{
Mohammadreza Vafa ${ }^{1,2}$, Fatemeh Azizi-Soleiman ${ }^{3}$, Seyyed Morteza Kazemi ${ }^{4}$, Masoud Salehi ${ }^{5}$, Farid Zaeri ${ }^{6}$, Behnaz Abiri $^{7}$, \\ Homa Sadeghi ${ }^{8}$, Morteza Safavi*3
}

Received: 1 Nov 2016

Published: 3 Jul 2019

\section{Abstract}

Background: Low levels of 25-hydroxyvitamin D $(25(\mathrm{OH}) \mathrm{D})$ have been related to depression and anxiety. It seems that anemia is associated with vitamin D deficiency. We aimed to evaluate the effects of iron-vitamin D co-supplementation versus vitamin D alone on depression scores in anemic females with low levels of serum 25-hydroxyvitamin D.

Methods: This randomized controlled trial was conducted on eighty premenopausal females who were recruited between May 2015 and October 2015 from primary health care centers. Women with anemia and low concentrations of $25(\mathrm{OH}) \mathrm{D}$ were randomized to either $1000 \mathrm{IU} / \mathrm{d}$ vitamin D plus $27 \mathrm{mg} / \mathrm{d}$ iron (D-Fe) or vitamin D plus placebo supplements (D-P) for 12 weeks. Depressive and anxious symptoms were evaluated with the Beck Depression Inventory (BDI) with subscales 1-13 and 14-21 and Beck Anxiety Inventory (BAI). To compare the groups, Mann-Whitney or chi-squared tests were used and within groups comparison was performed using Wilcoxon signed ranks test. The study was registered on www.clinicaltrial.org as NC 01876563.

Results: The serum concentrations of $25(\mathrm{OH}) \mathrm{D}$ were increased significantly in both groups at the end of the study. In both groups, there was a significant improvement in total BDI, the BDI subscale, and the BAI scores $(p<0.001)$. No differences were found between groups ( $>0.05)$.

Conclusion: Although the potential positive effect of vitamin D on mental health was evident, iron plus vitamin D cosupplementation did not demonstrate any significant benefits over vitamin D alone, neither in depression score reduction nor anxiety symptoms.

Keywords: Iron, Vitamin D, Depression, Anxiety, Anemia

Conflicts of Interest: None declared

Funding: Isfahan University of Medical Sciences, Iran University of Medical Sciences

\section{*This work has been published under CC BY-NC-SA 1.0 license.}

Copyright $\odot$ Iran University of Medical Sciences

Cite this article as: Vafa M, Azizi-Soleiman F, Kazemi SM, Salehi M, Zaeri F, Abiri B, Sadeghi H, Safavi M. Comparing the effectiveness of vitamin D plus iron vs vitamin D on depression scores in anemic females: Randomized triple-masked trial. Med J Islam Repub Iran. 2019 (3 Jul);33:64. https://doi.org/10.47176/mjiri.33.64

\section{Introduction}

Vitamin D plays a lot of roles in the body, including intestinal calcium and phosphorus absorption, mobilization

Corresponding author: Dr Morteza Safavi, dr.mortezasafavi@aol.com

1. Department of Nutrition, School of Public Health, Iran University of Medical Sciences, Tehran, Iran

2. Pediatric Growth and Development Research Center, Institute of Endocrinology and Metabolism, Iran University of Medical Sciences, Tehran, Iran

3. Department of Clinical Nutrition, School of Nutrition \& Food Science, Isfahan University of Medical Sciences, Isfahan, Iran

4. Bone, Joint, and Related Tissue Research Center, Akhtar Hospital, Shahid Beheshti University of Medical Sciences, Tehran, Iran

5. Department of Biostatistics, School of Public Health, Iran University of Medical Sciences, Tehran, Iran

6. Department of Biostatistics, Faculty of Paramedical Sciences, Shahid Beheshti University of Medical Sciences, Tehran, Iran

7. Department of Nutrition, Faculty of Paramedicine, Ahvaz Jundishapur University of Medical Sciences, Ahvaz, Iran

8. School of Public Health, Department of Nutrition and Food Science, Texas Woman's University, TX 76204, Denton Campus of calcium from bone, renal reabsorption of calcium and phosphorus, osteoclastogenesis, osteoclast activation, and

$\uparrow$ What is "already known" in this topic:

Low levels of 25-hydroxyvitamin D are thought to be related to depression and anxiety. On the other hand, recent studies have suggested a relationship between vitamin $\mathrm{D}$ and iron deficiencies.

$\rightarrow$ What this article adds:

Co-supplementation of vitamin D and iron compared with vitamin D alone yielded no added benefits for depression improvement in females with anemia and vitamin D insufficiency. 
suppression of parathyroid cell growth and parathyroid hormone gene expression (1). It has also been related to chronic diseases like type I diabetes, rheumatoid arthritis, Crohn's disease, multiple sclerosis, heart disease, stroke, infectious diseases, as well as increased risk of different types of cancers. Vitamin D deficiency has become epidemic worldwide due to sun exposure avoidance as a result of clothing, using sunscreen, and air pollution $(2,3)$.

Vitamin D receptors (VDR) are found in brain neurons. It has shown that vitamin $\mathrm{D}$ can regulate neurotrophic factors in the brain such as nerve growth factor (NGF), neurotrophin 3 and 4 (NT), and glial cell line-derived neurotrophic factor (GDNF). It has also been postulated that vitamin $\mathrm{D}$ may be neuroprotective through the synthesis of $\mathrm{Ca}^{2+}$-binding proteins such as parvalbumin (4). A crosssectional study conducted among older adults demonstrated that serum levels of $25-\mathrm{OH}$ vitamin $\mathrm{D}(25(\mathrm{OH}) \mathrm{D})$ were significantly lower in depressed patients after controlling for confounders (5).

Vitamin D Responsive Elements have been discovered in the promoter regions of two genes associated with depression (6). The health in men study, a recent study among 3105 older men, reported that vitamin D concentration $<50 \mathrm{nmol} / \mathrm{L}$ was associated with increased risk of current depression with odds of 1.65 (95\% confidence interval $=1.13-2.42)(7)$. It appears that the interaction between vitamin $\mathrm{D}$, dopamine and serotonin neurotransmitter systems, as well as circadian system is involved in depression symptoms (8).

Obesity is associated with depression, especially in females because of stigmatism (9). Vitamin D supplementation has been shown to be associated with a significant improvement in depression scores after one year in overweight and obese subjects (10).

Recent novel studies have proposed a relationship between vitamin D and iron deficiencies $(11,12)$. After skin exposure to sunlight and synthesizing vitamin D3 from 7dehydrocholesterol, it is hydroxylated twice in the liver and then in the kidneys to be activated (13). The next hydroxylase, renal-25(OH)D3-1 $\alpha$-hydroxylase, is a kind of cytochrome $\mathrm{P} 450$ which needs iron for its function. Therefore, iron deficiency may prevent vitamin $\mathrm{D}$ activation.

To our knowledge, there are no studies examining the relationship between serum levels of $25(\mathrm{OH}) \mathrm{D}$ and depression symptoms in anemic females with low levels of vitamin $\mathrm{D}$. In addition, whether iron-vitamin $\mathrm{D}$ cosupplementation provides additional mental health benefits beyond those of vitamin $\mathrm{D}$ alone, has to date not been investigated. To eliminate this gap, we conducted a randomized triple-masked clinical trial to assess whether iron-vitamin D co-supplementation would lead to remarkable improvement in depression scores in anemic people with low levels of serum $25(\mathrm{OH}) \mathrm{D}$.

\section{Methods}

We recruited non-smoking, non-pregnant, non-breastfeeding healthy women, 18 to 45 years of age with body mass index (BMI) between 18.5 and $29.9 \mathrm{~kg} / \mathrm{m}^{2}$ attending primary health care centers of Kermanshah Province, Iran. The screening procedure was established in May, 2015 and finished after 4 weeks. The intervention was conducted between July 2015 and October 2015. The required sample size was calculated from the difference of 21.1 points in $25(\mathrm{OH}) \mathrm{D}$ between the D-Fe and D-P groups after 12 weeks (14). We estimated that with a sample size of 32 participants in each group, the study would have more than $90 \%$ power to detect the between-group difference, with a 5\% (two-sided) type I error. Considering 20\% dropout rate in each group, the final sample size was determined to be 40 participants per group. A total of 700 females underwent the screening process. At attendance, blood samples were drawn for primary screening and secondary analysis of serum $25(\mathrm{OH}) \mathrm{D}$. Women who did not meet the inclusion criteria were excluded $(n=590)$. Thirty women had thalassemia and were excluded. Finally, a total of 80 anemic women agreed to participate in the study. Those with hemoglobin $\leq 12.7 \mathrm{~g} / \mathrm{dL}$ and $25(\mathrm{OH}) \mathrm{D}$ concentration $<30 \mathrm{ng} / \mathrm{mL}$ were assigned to one of the nutritional intervention groups unless they had any of the following exclusion criteria: consumption of vitamin D, iron supplements, and anti-depressant drugs within the previous 4 months, history of diseases like diabetes, thyroid disorders, amenorrhea (lack of menstruation in the 3 months prior to the study), menopause, iron-metabolismrelated diseases, gastrointestinal diseases, renal disease, or blood donor status. After provision of written informed consent, the participants were randomized into two groups: an iron-vitamin D group who was given 1000 IU/d vitamin D plus $27 \mathrm{mg} / \mathrm{d}$ iron and a vitamin Dplacebo group given the same amount of vitamin D plus iron placebo (starch) per day. The placebo tablets were identical in size, shape, and color to the iron tablets but contained no iron. An independent researcher unaware of the design and purpose of the study developed a random allocation sequence using a computer to randomly allocate 80 patients into 2 groups in a 1:1 ratio. The iron and placebo tablets were pre-packed in boxes and consecutively numbered according to the randomization list. The numbered boxes strategy was used for concealment. The boxes were stored in opaque envelopes until the study supervisor started random allocation after the eligibility of the patient was confirmed. Each person was assigned an order number and received the supplements in the corresponding pre-packed box. Participants, study supervisor, staff involved in outcome assessment, and statistician were blinded to treatment assignment. The blinding was conducted using the same strategy of allocation concealment by numbered boxes. The intervention consisted of a $12-$ week long, randomized, placebo-controlled, triplemasked, parallel-design trial. The subjects were supplied with new tablets every month. Treatment compliance was evaluated based on taking $>80 \%$ of the assigned supplements during the study. This study followed the CONSORT guidelines (15) and the study protocol was approved by Isfahan University of Medical Sciences ethics committee and was registered at www.clinicaltrial.org as NC 01876563.

\section{Primary outcome}

The primary outcome was the rate change in the con- 
centration of $25(\mathrm{OH}) \mathrm{D}$, which can improve depressed mood. Serum samples for $25(\mathrm{OH}) \mathrm{D}$ from baseline and 12 weeks were stored at $-80^{\circ \mathrm{C}}$ and analyzed after the study was completed. Serum vitamin D was measured by an ELISA kit, with intra- and inter-assay coefficients of variation of 5.6 and $6.4 \%$, respectively (25-hydroxyvitamin D EIA, Immunodiagnostic Systems, IDS, United Kingdom).

\section{Secondary outcomes}

Secondary outcomes included BDI, BAI, hemoglobin, and Body mass index (BMI) which were measured at preand post-intervention. The validated Iranian version of the Beck Depression Inventory (BDI) was used. BDI compromises 21 self-report questions that each item scores ranging from 0 to 3 and final scores range from 0 to 63 . The standard cut-off scores are as follows: 0-9: minimal depression; 10-18: mild depression; 19-29: moderate depression; and 30-63: severe depression. Its reliability and validity have been affirmed as an instrument to evaluate treatment response when used in interventional studies (16). The obtained score was also split up into two subscales, BDI 1-13 and BDI 14-21, representing cognitiveaffective and somatic-vegetative symptoms. The validated Iranian version of the Beck Anxiety Inventory (BAI) is a 21-item self-report questionnaire used to measure anxiety. Scoring the BAI is based on a $0-3$ point scale with a maximum score of 63 . The following ranges of BAI are suggested for anxiety: 8-15: mild anxiety; 16-25: moderate anxiety; and 26-63: severe anxiety. Using whole blood samples, hemoglobin was defined using the Symex NE 9100 automated hematology analyzer (Symex, Kobe, Japan). A digital scale was used to measure body weight to the nearest $100 \mathrm{~g}$ (BF54; Beurer, Germany) with light clothing and without shoes. Height was measured without shoes against a wall-fixed tape to the nearest $0.01 \mathrm{~cm}$. BMI was calculated by dividing body weight in kilograms by body height squared in meters. International Physical Activity Questionnaire, short format (17) was filled in by participants. The amount of physical activity was calculated and reported in units of metabolic equivalents (MET)- hours per day.

\section{Statistical analyses}

Based on the Kolmogorov-Smirnov test, the dependent variables were not normally distributed, except for BMI. Baseline values of physical activity score and $25(\mathrm{OH}) \mathrm{D}$ attained normal distribution after logarithmic transformation. In other cases, nonparametric statistics were used. Comparisons between groups were performed with the Mann-Whitney, independent samples t-test, and chisquared test and within groups with the Wilcoxon signed ranks test. The Spearman's correlation coefficient was used for evaluating correlations. Data are expressed as mean $(95 \% \mathrm{CI})$ or median (interquartile range, IQR). Analysis of covariance (ANCOVA) was used for adjusting baseline measurements of dependent variables. A pvalue $<0.05$ was considered as statistically significant. The SPSS version 22.0 was used for all statistical analyses.

\section{Results}

At the baseline, there were no significant differences between groups (Table 1). Of the 80 females participated in the interventions, one person in the D-P group and 5 persons in the D-Fe group, dropped out because of noncompliance. Thus, 74 individuals completed the study (Fig. 1).

At baseline, total BDI score was negatively correlated with BMI (rho= $-0.351, \mathrm{p}=0.002$ ). This relation was also seen between BDI 1-13 and BMI ( $r h o=-0.422, p<0.001)$. There was no significant correlation between total BAI score and other variables including age, serum $25(\mathrm{OH}) \mathrm{D}$, BMI, and physical activity levels (Table 2).

After 12 weeks, the serum concentration of $25(\mathrm{OH}) \mathrm{D}$ increased significantly in both groups. There was no significant change in BMI in any of the groups. A statistically significant reduction in the total BDI, the BDI subscale, and the total BAI scores was demonstrated in all participants (Table 3). However, the differences in none of the variables were significant between the groups, even after

Table 1. Baseline characteristics of study participants

\begin{tabular}{lcc}
\hline Variable & $\begin{array}{c}\text { Vitamin D-Iron } \\
(\mathrm{n}=40)\end{array}$ & $\begin{array}{c}\text { Vitamin D-Placebo } \\
(\mathrm{n}=40)\end{array}$ \\
\hline Age, y: median (IQR) & $38.50(28.75-42.00)$ & $40.00(33.50-42.50)$ \\
BMI, kg/m²: mean (95\% CI) & $27.76(25.80,29.71)$ & $28.51(26.85,30.16)$ \\
Married, n (\%) & $28(70)$ & $32(80)$ \\
Physical activity score (MET-minutes/week): mean (95\% CI) & $811.21(370.79,1774.79)$ & $862.88(403.46,1845.46)$ \\
Depressive symptoms score (BDI): median (IQR) & $12.00(3.00-20.75)$ & $0.560^{\dagger}$ \\
Anxious symptoms score (BAI): median (IQR) & $16.50(3.00-13.25)$ & $0.177^{\ddagger}$ \\
Serum 25(OH)D, ng/ml: mean (95\% CI) & $17.02(12.91,22.43)$ & $10.00(4.00-14.00)$ \\
\hline
\end{tabular}

Serum $25(\mathrm{OH}) \mathrm{D}, \mathrm{ng} / \mathrm{ml}$ : mean $(95 \% \mathrm{CI})$

Obtained from Mann-Whitney test

Obtained from independent samples t-test

‡Obtained from Chi-Square test

Table 2. Correlations between variables

\begin{tabular}{|c|c|c|c|c|}
\hline Variable & BDI total score & BAI total score & BDI (1-13) score & BDI (14-21) score \\
\hline Age (y) & -0.127 & 0.220 & -0.172 & 0.000 \\
\hline BMI $\left(\mathrm{kg} / \mathrm{m}^{2}\right)$ & $-0.351^{*}$ & -0.017 & $-0.422^{\dagger}$ & -0.165 \\
\hline Physical activity score (MET-minutes/week) & 0.003 & -0.006 & 0.027 & -0.011 \\
\hline Serum $25(\mathrm{OH}) \mathrm{D}(\mathrm{ng} / \mathrm{ml})$ & 0.021 & 0.044 & 0.035 & 0.002 \\
\hline
\end{tabular}

$\mathrm{P}<0.05$

${ }^{\dagger} \mathrm{P}<0.001$

Data are expressed as Spearman's rho coefficients 


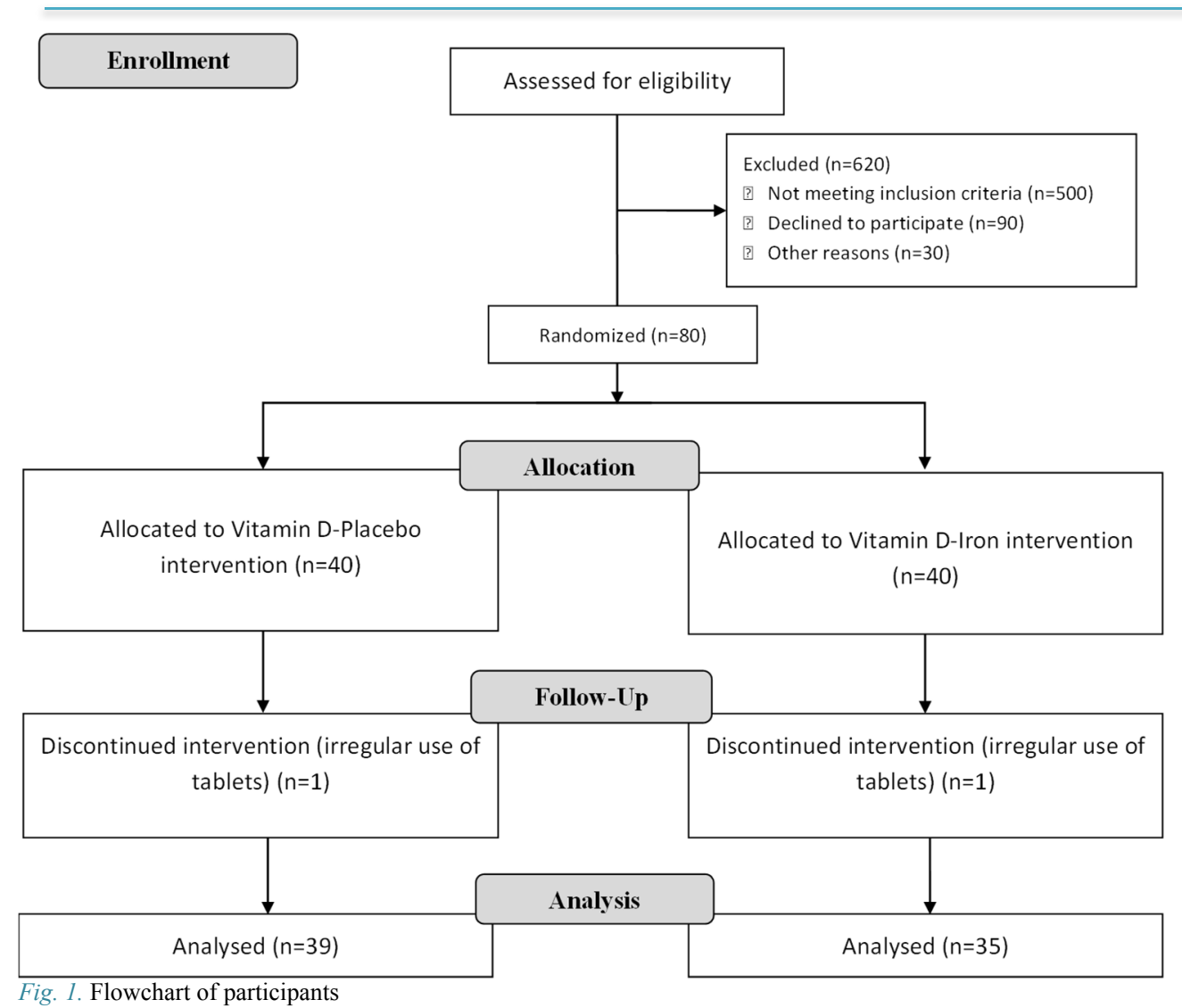

Table 3. Baseline and 12-week values according to treatment

\begin{tabular}{|c|c|c|c|c|c|c|c|}
\hline Variable & \multicolumn{3}{|c|}{ Vitamin D-Iron $(\mathrm{n}=35)$} & \multicolumn{3}{|c|}{ Vitamin D-Placebo $(n=39)$} & $\begin{array}{l}\mathrm{p} \text { for } \\
\text { changes }\end{array}$ \\
\hline $\begin{array}{l}\text { BMI, } \mathrm{kg} / \mathrm{m}^{2}: \text { mean }(95 \% \\
\text { CI) }\end{array}$ & $\begin{array}{c}\text { Baseline } \\
28.14 \\
(25.83,30.46)\end{array}$ & $\begin{array}{c}12 \text { weeks } \\
27.92 \\
(25.56,30.28)\end{array}$ & $\begin{array}{c}\text { Change } \\
-0.22 \\
(-0.57,+0.12)\end{array}$ & $\begin{array}{c}\text { Baseline } \\
28.29 \\
(26.62,29.96)\end{array}$ & $\begin{array}{c}12 \text { weeks } \\
28.15 \\
(26.40,29.90)\end{array}$ & $\begin{array}{c}\text { Change } \\
-0.14 \\
(-0.65,+0.37)\end{array}$ & $\begin{array}{c}\text { changes } \\
0.752^{\dagger}\end{array}$ \\
\hline $\begin{array}{l}\text { BDI total score, median } \\
\text { (IQR) }\end{array}$ & $\begin{array}{c}12.0 \\
(4.5-20.0)\end{array}$ & $\begin{array}{c}7.0 \\
(1.5-12.0)^{*}\end{array}$ & $-4(-1,-9)$ & $8.0(4.0-14.0)$ & $4.0(1.0-9.0)^{*}$ & $-3(-1,-6)$ & $0.586^{\ddagger}$ \\
\hline $\begin{array}{l}\text { BDI (1-13) score, median } \\
\text { (IQR) }\end{array}$ & $\begin{array}{c}7.0 \\
(2.5-14.5)\end{array}$ & $\begin{array}{c}4.0 \\
(1.0-9.0)^{*}\end{array}$ & $-1(+4,0)$ & $6.0(3.0-8.0)$ & $3.0(1.0-6.0)^{*}$ & $-1(+3,0)$ & $0.396^{\ddagger}$ \\
\hline $\begin{array}{l}\text { BDI (14-21) score, median } \\
\text { (IQR) }\end{array}$ & $\begin{array}{c}4.0 \\
(1.0-7.5)\end{array}$ & $\begin{array}{c}2.0 \\
(0.0-4.5)^{*}\end{array}$ & $-1(+3,0)$ & $2.5(1.0-6.0)$ & $1.0(0.0-3.0)^{*}$ & $-1(+3,0)$ & $0.996^{\ddagger}$ \\
\hline BAI score, median (IQR) & $\begin{array}{c}16.0 \\
(10.5-22.0)\end{array}$ & $\begin{array}{c}7.0 \\
(3.5-12.0)^{*}\end{array}$ & $-9(-6,-12)$ & $11.0(6.0-22.0)$ & $5.0(2.0-11.0)^{*}$ & $-6(-3,-11)$ & $0.204^{\ddagger}$ \\
\hline $\begin{array}{l}\text { Serum } 25(\mathrm{OH}) \mathrm{D}, \mathrm{ng} / \mathrm{ml} \text { : } \\
\text { median }(\mathrm{IQR})\end{array}$ & $\begin{array}{c}16.70 \\
(14.56,21.80)\end{array}$ & $\begin{array}{c}41.40 \\
(28.10,50.35)^{*}\end{array}$ & $\begin{array}{c}+21.70 \\
(+10.20,31.90)\end{array}$ & $\begin{array}{c}18.95 \\
(15.50,25.40)\end{array}$ & $\begin{array}{c}43.65 \\
(32.60,53.00)^{*}\end{array}$ & $\begin{array}{c}+20.55 \\
(+13.30,+30.80)\end{array}$ & $0.824^{\ddagger}$ \\
\hline
\end{tabular}

${ }^{*} \mathrm{P}<0.001 \mathrm{vs}$. baseline (Obtained from Wilcoxon test)

${ }^{\dagger}$ Obtained using Independent Samples T test

†Obtained using Mann-Whitney test

adjustment for baseline values. Figure 2 shows the distribution of the BAI and BDI scores at baseline and end of the study. The frequency of participants with lower anxiety and depression scores increased after the intervention in both groups.

In the D-Fe group, 8 participants had gastrointestinal side effects because of iron intake. Five of eight females were excluded from the study. There were no side effects from vitamin D.

\section{Discussion}

The present study demonstrated that addition of $27 \mathrm{mg} / \mathrm{d}$ iron to a supplementation regimen with $1000 \mathrm{IU} / \mathrm{d}$ cholecalciferol for 12 weeks in healthy women with low levels of hemoglobin and serum $25(\mathrm{OH}) \mathrm{D}$, was not superior to the vitamin $\mathrm{D}$ alone in improving BDI and BAI scores.
Both interventions were efficient in reducing depression and anxiety symptoms.

Some previous studies have shown a significant and negative relationship between serum $25(\mathrm{OH}) \mathrm{D}$ concentration and depression (18). In a study by Yilmaz et al., vitamin D level had a negative association with BDI scores in 214 premenopausal women $(r=-0.361, p<0.001)(19)$. No such relationship was found in the present study. Similarly, in a study by Nielsen et al., aimed to evaluate the correlation between vitamin $\mathrm{D}$ levels and depression in 605 women with postpartum depression and 875 controls, low concentration of $25(\mathrm{OH}) \mathrm{D}$ was not related to a greater risk of depression (20). Not measuring vitamin D binding protein and existence of some confounders were considered as possible explanation. However, recruiting healthy women and using BDI as a sole diagnostic measure might 

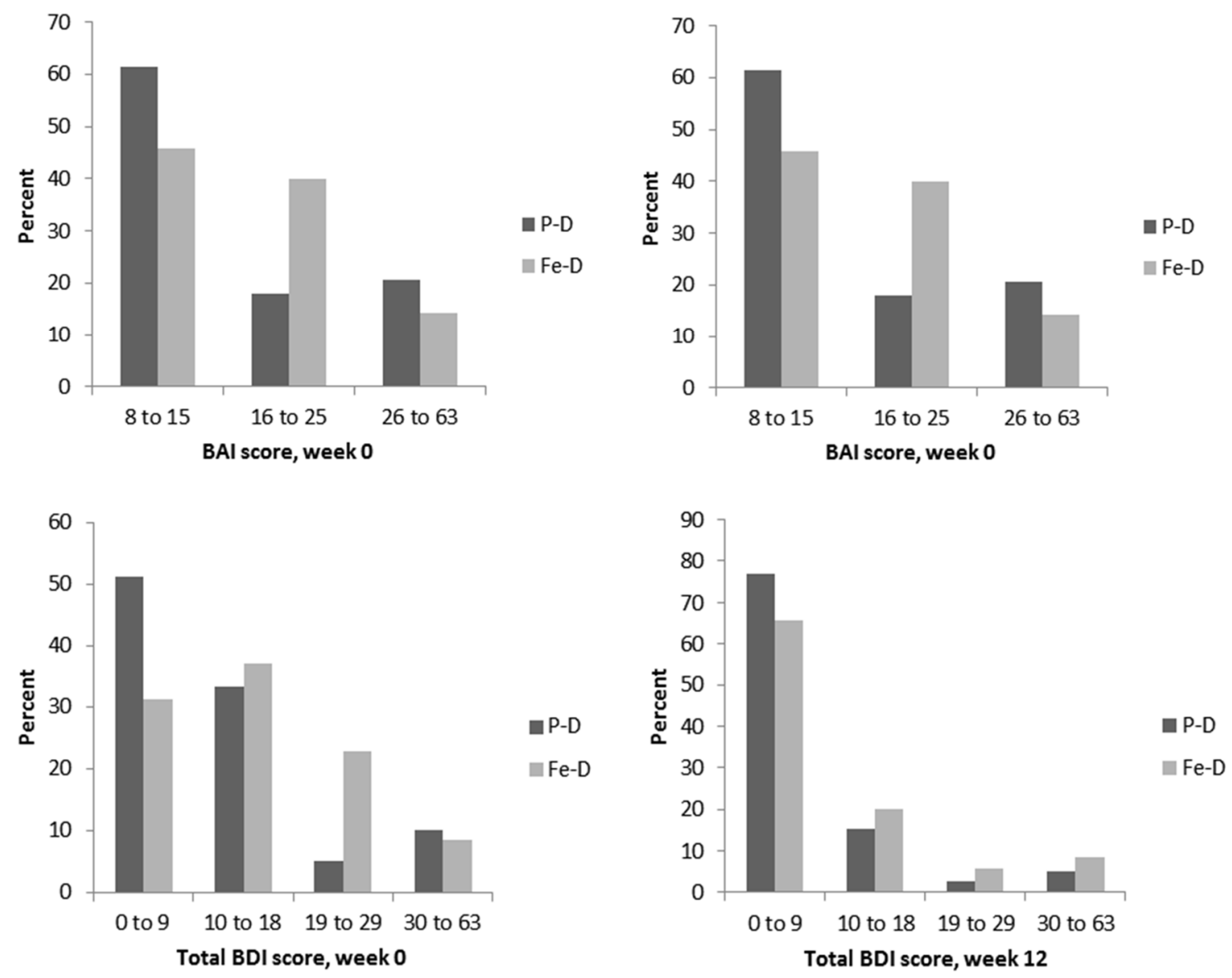

Fig. 2. Beck Anxiety Inventory (BAI) scores at baseline (a) and after 12 weeks (b); Total Beck Depression Inventory (BDI) scores at baseline (c) and after 12 weeks (d) in intervention groups. P-D: placebo-vitamin D and Fe-D: iron-vitamin D.

confound our results.

Unlike previous studies, we found that lower BMI was associated with higher depression scores. A recent metaanalysis discovered that obesity but not overweight was related bi-directionally to depression (21). Some researchers have revealed a U-shaped trend in the relationship between depression and BMI $(22,23)$. Being underweight or obese was related to an increased risk of depression. In the study by Lee and Yen, which included 5254 adolescents, there were no significant differences in depression between overweight/obese and average weight participants (24). We did not include obese females in our study and thus the present results may not be comparable with those in other studies. In addition, socioeconomic status (SES) is another factor influencing the association between body weight and depression. Being obese has been related to more depression symptoms in AfricanAmericans with lower SES (9). There are also other factors affecting the relationship between obesity and depression including genetic features, environmental, behavioral, and cognitive factors, unfavorable childhood experiences, marital status, education level, and stressful life events (9, $25,26)$. Unfortunately, we did not evaluate these variables in the current study, and it is recommended to evaluate these factors in the future studies.

Positive effects of vitamin D supplementation on psy- chologic symptoms are in line with earlier studies. A randomized double-blind placebo controlled study in which overweight and obese participants were given 20.000 or $40.000 \mathrm{IU} / \mathrm{w}$ vitamin D for 1 year, reported a significant improvement in BDI scores (10). In a study by Kjærgaard et al., 243 adults with low levels of serum $25(\mathrm{OH}) \mathrm{D}$ were randomized to either placebo or 40000 IU/w vitamin D3 for 6 months. No statistically significant differences between groups were found regarding depressive symptoms (27). These divergence results can be attributed to heterogeneity in the amount and duration of vitamin D supplementation, assessment of depression, follow-up periods, and study participants. There are several proposed mechanisms by which vitamin D might improve mood changes. The VDRs are distributed in the brain and the central nervous system contains enzymes necessary for the hydroxylation of this vitamin (28). These receptors are involved in affective disorders, serotonin synthesis and tryptophan hydroxylase gene regulation, and the production of proinflammatory cytokines that affect stress response $(6,29)$. Bertone-Johnson et al. previously in a randomized, double-blinded trial revealed that daily supplementation with 400 IU of vitamin $\mathrm{D}_{3}$ combined with $1,000 \mathrm{mg}$ of elemental calcium was not effective in the reduction of the risk of depression (30). As VDRs induce calcium uptake, they concluded that this finding 
might have been confounded by calcium supplementation. There are some confounding factors that may influence the relationship between vitamin $\mathrm{D}$ and depression such as age, physical activity, and body mass index (31). Our results are unlikely to be biased with these factors due to the absence of changes in any of the confounders.

We found that iron (neither through increasing vitamin $\mathrm{D}$ nor directly) could not affect mood. Iron is involved in the metabolism of neurotransmitters $(32,33)$. It is postulated that iron deficiency in brain tissue might be related to psychological impairments (34). The lack of effect of vitamin $\mathrm{D}$ plus iron compared to vitamin $\mathrm{D}$ alone might be due to several reasons. First of all, although all women had anemia, nearly half of them $(n=38)$ did not meet the criteria for iron deficiency anemia. It has shown that the activity of cytochrome P450 complex, including 25hydroxylase, reduces when iron depletion happens (35). Secondly, because of considering a wide range of hemoglobin, we selected an iron dose that just prevented a further reduction of iron stores. So, maybe insufficient intervention dose was used here. Measuring the expression of CYP27B1could improve our knowledge of underlying mechanisms.

\section{Strengths and limitations}

Some limitations in the present study should be noted. Firstly, the present results may not apply to the general population because of including only women with low $\mathrm{Hb}$ and $25(\mathrm{OH}) \mathrm{D}$ levels in the study. Secondly, only the BDI questionnaire was used, while simultaneous use of other widely used scales could have given us more information. Thirdly, females with a wide range of depression scores were included in the study. Another limitation is that the present study should have been performed in those with ferritin levels less than $30 \mathrm{ng} / \mathrm{ml}$. However, our study has several strengths. To our knowledge, our study is the first randomized trial to evaluate the consequences of concurrent vitamin D and iron supplementation on depressive symptoms. Additional strengths of our study include using a safe dose of vitamin $\mathrm{D}$ and iron and high adherence rate.

\section{Conclusion}

Simultaneous supplementation of iron and vitamin D does not yield added benefits for depression improvement in females with anemia and vitamin D insufficiency, compared with vitamin $\mathrm{D}$ alone. Both depressive and anxious symptoms were decreased after 12 weeks, but there were no significant differences between groups. The public health importance of our findings remains equivocal as long as the numbers of trials are scarce.

\section{Acknowledgments}

This study was extracted from Ph.D. dissertation which was approved by School of Nutrition \& Food Sciences, Isfahan University of Medical Sciences (code: IR.MUI.REC.1394.3/291). The authors are grateful to thank the volunteers who participated in the study.

\section{Conflict of Interests}

The authors declare that they have no competing interests.
References

1. Feldman D, Pike JW, Adams JS. Vitamin D. London ; Waltham, Mass.: Academic Press,; 2011. Available from:http:// proxyhu.wrlc.org/login?url=http://www.clinicalkey.com/dura/browse/ bookChapter/3-s2.0-C20091634067.

2. Rabenberg M, Scheidt-Nave C, Busch MA, Rieckmann N, Hintzpeter B, Mensink GB. Vitamin D status among adults in Germany--results from the German Health Interview and Examination Survey for Adults (DEGS1). BMC Public Health. 2015;15:641.

3. Grober U, Spitz J, Reichrath J, Kisters K, Holick MF. Vitamin D: Update 2013: From rickets prophylaxis to general preventive healthcare. Dermato-endocrinol. 2013;5:331-47.

4. Buell JS, Dawson-Hughes B. Vitamin D and neurocognitive dysfunction: preventing "D"ecline? Mol Aspects Med. 2008;29:415 22 .

5. Voshaar RO, Derks W, Comijs H, Schoevers R, De Borst M, Marijnissen R. Antidepressants differentially related to 1, 25-(OH) 2 vitamin D3 and 25-(OH) vitamin D3 in late-life depression. Transl Psychiatr. 2014;4:e383.

6. de Abreu DF, Eyles D, Feron F. Vitamin D, a neuroimmunomodulator: implications for neurodegenerative and autoimmune diseases. Psychoneuroendocrinology. 2009;34:S265-S77.

7. Almeida OP, Hankey GJ, Yeap BB, Golledge J, Flicker L. Vitamin D concentration and its association with past, current and future depression in older men: The Health In Men Study. Maturitas. 2015;81:36-41.

8. Stewart AE, Roecklein KA, Tanner S, Kimlin MG. Possible contributions of skin pigmentation and vitamin $\mathrm{D}$ in a polyfactorial model of seasonal affective disorder. Med Hypotheses. 2014;83:51725 .

9. Sachs-Ericsson N, Burns AB, Gordon KH, Eckel LA, Wonderlich SA, Crosby RD, et al. Body mass index and depressive symptoms in older adults: the moderating roles of race, sex, and socioeconomic status. Am J Geriatr Psychiatry. 2007;15:815-25.

10. Jorde R, Sneve M, Figenschau Y, Svartberg J, Waterloo K. Effects of vitamin D supplementation on symptoms of depression in overweight and obese subjects: randomized double blind trial. J Intern Med. 2008;264:599-609.

11. Kang YS, Kim JH, Ahn EH, Yoo EG, Kim MK. Iron and vitamin D status in breastfed infants and their mothers. Korean J Pediatr. 2015;58:283-7.

12. Yoo EH, Cho HJ. Prevalence of 25-hydroxyvitamin D deficiency in Korean patients with anemia. J Clin Lab Anal. 2015;29:129-34.

13. Watson RR. Handbook of vitamin D in human health prevention, treatment and toxicity. Wageningen: Wageningen Academic Publishers; 2013.

14. Shab-Bidar S, Neyestani TR, Djazayery A. Efficacy of vitamin D3fortified-yogurt drink on anthropometric, metabolic, inflammatory and oxidative stress biomarkers according to vitamin D receptor gene polymorphisms in type 2 diabetic patients: a study protocol for a randomized controlled clinical trial. BMC endocrine disorders. 2011;22:11-12.

15. Schulz KF, Altman DG, Moher D. CONSORT 2010 statement: updated guidelines for reporting parallel group randomised trials. BMC Medicine. 2010;8:1.

16. Beck AT, Ward CH, Mendelson M, Mock J, Erbaugh J. An inventory for measuring depression. Arch Gen Psychiatry. 1961;4:561-71.

17. Moghaddam MHB, Aghdam FB, Jafarabadi MA, Allahverdipour H, Nikookheslat SD, Safarpour S. The Iranian Version of International Physical Activity Questionnaire (IPAQ) in Iran: content and construct validity, factor structure, internal consistency and stability. World Appl Sci. 2012;18:1073-80.

18. Knippenberg S, Bol Y, Damoiseaux J, Hupperts R, Smolders J. Vitamin D status in patients with MS is negatively correlated with depression, but not with fatigue. Acta Neurol Scand. 2011;124:171-5.

19. Yilmaz H, Bodur S, Karaca G. The association between vitamin D level and chronic pain and depression in premenopausal women/Premenopozal eriskin kadinlarda vitamin D duzeyi ile kronik agri ve depresyon arasindaki iliski. Turk J Phys Med Rehabil. 2014;60:121-6.

20. Nielsen NO, Strøm M, Boyd HA, Andersen EW, Wohlfahrt J, Lundqvist $\mathrm{M}$, et al. Vitamin D status during pregnancy and the risk of subsequent postpartum depression: a case-control study. PloS One. 2013;8:e80686. 
21. Mannan M, Mamun A, Doi S, Clavarino A. Is there a bi-directional relationship between depression and obesity among adult men and women? Systematic review and bias-adjusted meta analysis. Asian J Psychiatry. 2016;21:51-66.

22. De Wit LM, Van Straten A, Van Herten M, Penninx BW, Cuijpers P. Depression and body mass index, a u-shaped association. BMC public health. 2009;9:1.

23. Martin-Rodriguez E, Guillen-Grima F, Aubá E, Martí A, BrugosLarumbe A. Relationship between body mass index and depression in women: A 7-year prospective cohort study. The APNA study. Eur Psychiatry. 2016;32:55-60.

24. Lee JI, Yen CF. Associations between body weight and depression, social phobia, insomnia, and self-esteem among Taiwanese adolescents. Kaohsiung J Med Sci. 2014;30:625-30.

25. Carr D, Friedman MA, Jaffe K. Understanding the relationship between obesity and positive and negative affect: the role of psychosocial mechanisms. Body Image. 2007;4:165-77.

26. Simon GE, Ludman EJ, Linde JA, Operskalski BH, Ichikawa L, Rohde $\mathrm{P}$, et al. Association between obesity and depression in middleaged women. Gen Hosp Psychiatry. 2008;30:32-9.

27. Kjærgaard $\mathrm{M}$, Waterloo $\mathrm{K}$, Wang $\mathrm{CE}$, Almås $\mathrm{B}$, Figenschau $\mathrm{Y}$, Hutchinson MS, et al. Effect of vitamin D supplement on depression scores in people with low levels of serum 25-hydroxyvitamin D: nested case-control study and randomised clinical trial. $\mathrm{Br} \mathrm{J}$ Psychiatry. 2012;201:360-8.

28. May HT, Bair TL, Lappé DL, Anderson JL, Horne BD, Carlquist JF, et al. Association of vitamin D levels with incident depression among a general cardiovascular population. Am Heart J. 2010;159:1037-43.

29. Kerr DC, Zava DT, Piper WT, Saturn SR, Frei B, Gombart AF. Associations between vitamin D levels and depressive symptoms in healthy young adult women. Psychiatry Res. 2015;227:46-51.

30. Bertone-Johnson ER, Powers SI, Spangler L, Larson J, Michael YL, Millen AE, et al. Vitamin D supplementation and depression in the women's health initiative calcium and vitamin D trial. Am J Epidemiol. 2012;176:1-13.

31. Chung HK, Cho Y, Choi S, Shin MJ. The association between serum 25-hydroxyvitamin D concentrations and depressive symptoms in Korean adults: findings from the fifth Korea National Health and Nutrition Examination Survey 2010. PLoS One. 2014;9:e99185.

32. Beard JL. Iron biology in immune function, muscle metabolism and neuronal functioning. J Nutr. 2001;131:568S-579S

33. Erikson KM, Jones BC, Hess EJ, Zhang Q, Beard JL. Iron deficiency decreases dopamine D1 and D2 receptors in rat brain. Pharmacol Biochem Behav. 2001;69:409-18.

34. Vaucher P, Druais PL, Waldvogel S, Favrat B. Effect of iron supplementation on fatigue in nonanemic menstruating women with low ferritin: a randomized controlled trial. Can Med Assoc J. 2012;184:1247-54.

35. hur A, Galan P, Hercberg S. Effects of different degrees of iron deficiency on cytochrome P450 complex and pentose phosphate pathway dehydrogenases in the rat. J Nutr. 1989;119:40-7. 